\title{
BMJ Open African-American patients with cancer Talking About Clinical Trials (TACT) with oncologists during consultations: evaluating the efficacy of tailored health messages in a randomised controlled trial - the TACT study protocol
}

\author{
R F Brown, ${ }^{1}$ R Davis, ${ }^{2}$ M Wilson Genderson, ${ }^{3}$ S Grant, ${ }^{4}$ D Cadet, ${ }^{4}$ M Lessard, \\ J Alpert, ${ }^{1} \mathrm{~J}$ Ward, ${ }^{1} \mathrm{G}$ Ginder ${ }^{4}$
}

To cite: Brown RF, Davis R, Wilson Genderson M, et al. African-American patients with cancer Talking About Clinical Trials (TACT) with oncologists during consultations: evaluating the efficacy of tailored health messages in a randomised controlled trial一-the TACT study protocol. BMJ Open 2016;6:e012864.

doi:10.1136/bmjopen-2016012864

- Prepublication history and additional material is available. To view please visit the journal (http://dx.doi.org/ 10.1136/bmjopen-2016012864)

Received 31 May 2016 Revised 24 October 2016 Accepted 11 November 2016

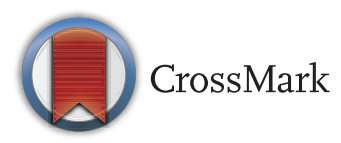

For numbered affiliations see end of article.

Correspondence to Dr RF Brown; Richard. Brown@VcuHealth.org

\section{ABSTRACT}

Introduction: Low rates of accrual of AfricanAmerican (AA) patients with cancer to therapeutic clinical trials (CTs) represent a serious and modifiable racial disparity in healthcare that impedes the development of promising cancer therapies. Suboptimal physician-patient consultation communication is a barrier to the accrual of patients with cancer of any race, but communication difficulties are compounded with AA patients. Providing tailored health messages (THM) to AA patients and their physician about CTs has the potential to improve communication, lower barriers to accrual and ameliorate health disparities.

Objective: (1) Demonstrate the efficacy of THM to increase patient activation as measured by direct observation. (2) Demonstrate the efficacy of THM to improve patient outcomes associated with barriers to AA participation. (3) Explore associations among preconsultation levels of: $(A)$ trust in medical researchers, (B) knowledge and attitudes towards CTs, (C) patient-family member congruence in decisionmaking, and (D) involvement/information preferences, and group assignment.

Methods and analysis: First, using established methods, we will develop THM materials. Second, the efficacy of the intervention is determined in a 2 by 2 factorial randomised controlled trial to test the effectiveness of (1) providing 357 AA patients with cancer with THM with 2 different 'depths' of tailoring and (2) either providing feedback to oncologists about the patients' trial THM or not. The primary analysis compares patient engaged communication in 4 groups preconsultation and postconsultation.

Ethics and dissemination: This study was approved by the Virginia Commonwealth University Institutional Review Board. To facilitate use of the THM intervention in diverse settings, we will convene 'user groups' at 3 major US cancer centres. To facilitate dissemination,

\section{Strengths and limitations of this study}

- This study is designed to overcome significant health disparities by improving AfricanAmerican-oncologist communication about therapeutic clinical trials.

- This study will extend our knowledge of tailored health messaging.

- This study is a randomised controlled trial of tailored health messaging in a novel setting, cancer clinical trial communication.

- We have limited capacity to assess the differential efficacy of the intervention between phase I, II and III clinical trials.

- This study is being conducted at one academic cancer centre, thus communication issues particular to the community oncology setting will not be assessed.

we will post all materials and the implementation guide in publicly available locations.

Trial registration number: NCT02356549.

\section{INTRODUCTION}

The cancer mortality rate in the USA is $33 \%$ higher for African-Americans (AA) than for white Americans and AA have the lowest 5 -year survival rates when compared with all other racial groups. ${ }^{1}$ In the USA, the National Cancer Institute, the American Cancer Society and the American Society for Clinical Oncology have recognised and reported the unequal burden of cancer in AA patients and their low representation in 
clinical trials (CTs). The effectiveness of this translational process is greatly dependent on the number and representativeness of participants enrolled in trials, yet $<5 \%$ of all adult patients with cancer enter CTs and even lower participation rates are reported in minority populations, including $\mathrm{AA}^{2-4}$

Inequitable participation in state of the art cancer care contributes to health disparities in cancer mortality and survival between AA and whites. ${ }^{5}{ }^{6}$ Specifically, low representation of AA patients in CTs compromises the generalisability and external validity of trial results, ${ }^{7} 8$ and may fail to identify important positive or negative treatment effects among under-represented populations. ${ }^{9}{ }^{10}$ Barriers to minority patients' participation in CTs include systemic factors, ${ }^{11}{ }^{12}$ such as strict exclusion criteria, ${ }^{11}$ which limit AA opportunities to participate. ${ }^{12}$ However, studies suggest that racial differences in patient barriers to participation are due in part to nonclinical factors related to poor trial information, ${ }^{13}{ }^{14}$ mistrust of medical research, ${ }^{15}$ family pressures ${ }^{12}$ and poor communication with physicians. ${ }^{5} 1116$ Thus, high-quality physician-patient communication is key to increasing the active engagement of AA patients in decision-making about CTs. Yet, there is mounting evidence about the communication challenges present in treatment discussions, ${ }^{16-31}$ including CTs that are compounded with AA patients. ${ }^{32}{ }^{33}$ Racial disparities in communication could lead to less informed decisions ${ }^{34}$ and lower trust in physicians. ${ }^{34}$ As such, there is a critical need to develop communication interventions to modify barriers to recruitment and hopefully ameliorate health disparities and optimise the benefits of CTs. ${ }^{561135}$

One communication method that has demonstrated efficacy to promote patient activation (characterised by asking questions, expressing concerns and being assertive) in consultation communication is providing tailored health messages (THM) ${ }^{36}$ THM increase the relevance of health information by targeting individuals' personalised needs based on a rigorous assessment of their characteristics and preferences ${ }^{37}$ and have been successfully used to promote AA cancer screening behaviours. ${ }^{38}$ The process of tailoring health messages involves collecting data (usually by way of a comprehensive survey) about the receiver's needs and preferences and then preparing individually customised materials (eg, print materials or online tools) that meet these needs.

Evidence indicates that THM interventions are effective; ${ }^{39}$ however, research is still needed to explicitly explore factors that most contribute to their success. The exact number of variables needed and the level and intensity of tailoring (depth of tailoring) required to achieve research goals is not known. Physician-patient communication is known to be a dynamic process; yet, no studies, to the best of our knowledge, have explored the impact of involving patients and physicians in THM interventions that target cancer CT consultations. The goal of this study is to test the efficacy of (1) providing AA patients with cancer with tailored CT messages with two different depths of tailoring and (2) either providing feedback to oncologists about the patients' tailored CT messages or not.

To the best of our knowledge, this is the first randomised controlled trial (RCT) which assesses the efficacy of a THM intervention on AA patients with cancer (1) active communication in CT consultations as measured by objective coding of consultation audio recordings, (2) self-reported barriers to joining CTs, and (3) satisfaction and decision-related outcomes.

\section{METHODS AND ANALYSIS \\ Study design}

This study is an RCT using a two by two factorial design. Equal numbers of participants are randomly assigned to one of four intervention groups.

This study follows CONSORT guidelines (figure 1). ${ }^{40}$

Group 1 (n=89): shallow tailoring-Patients receive THMs based only on demographic and disease information extracted from their electronic medical records (EMR). These variables include (1) demographic information: age, income, education and health insurance status; (2) disease variables: cancer type and severity; and (3) trial variables: phase of trial being offered and prior trial participation.

Group 2 ( $n=89)$ : shallow tailoring+physician involvementPatients receive THMs based on EMR data, and their physicians receive a summary of the THMs that are provided to the patients.

Group 3 (n=89): deep tailoring-Patients receive THMs based on EMR data as well as data derived from a survey that patients completed on enrolment.

Group 4 (n=89): deep tailoring+physician involvementPatients receive THMs based on EMR and survey data, and their physicians receive a summary of the THMs that are provided to the patients (figure 2).

\section{Intervention}

\section{Tailored message development}

THMs were developed using guidelines presented in the health communication literature. ${ }^{41}{ }^{42}$ Many THM interventions are based on the input of data collected by means of a comprehensive survey to produce messages that are matched to an individual recipient's needs and preferences. However, patient data to inform tailoring can also be generated by accessing patient data through EMR. ${ }^{37}$ As we intend to explore the impact of different 'depths' of tailoring, we use both comprehensive surveys and EMR data to generate patient data to produce two types of THM.

The first step to develop the THMs is to generate patient data to develop tailored messages about CTs. To achieve this, we extract patient demographic and disease variables and information about their CT experience from patients' EMR and use these data to generate a 'shallow' level of tailoring. These data include: (1) demographic information such as age, education level, 


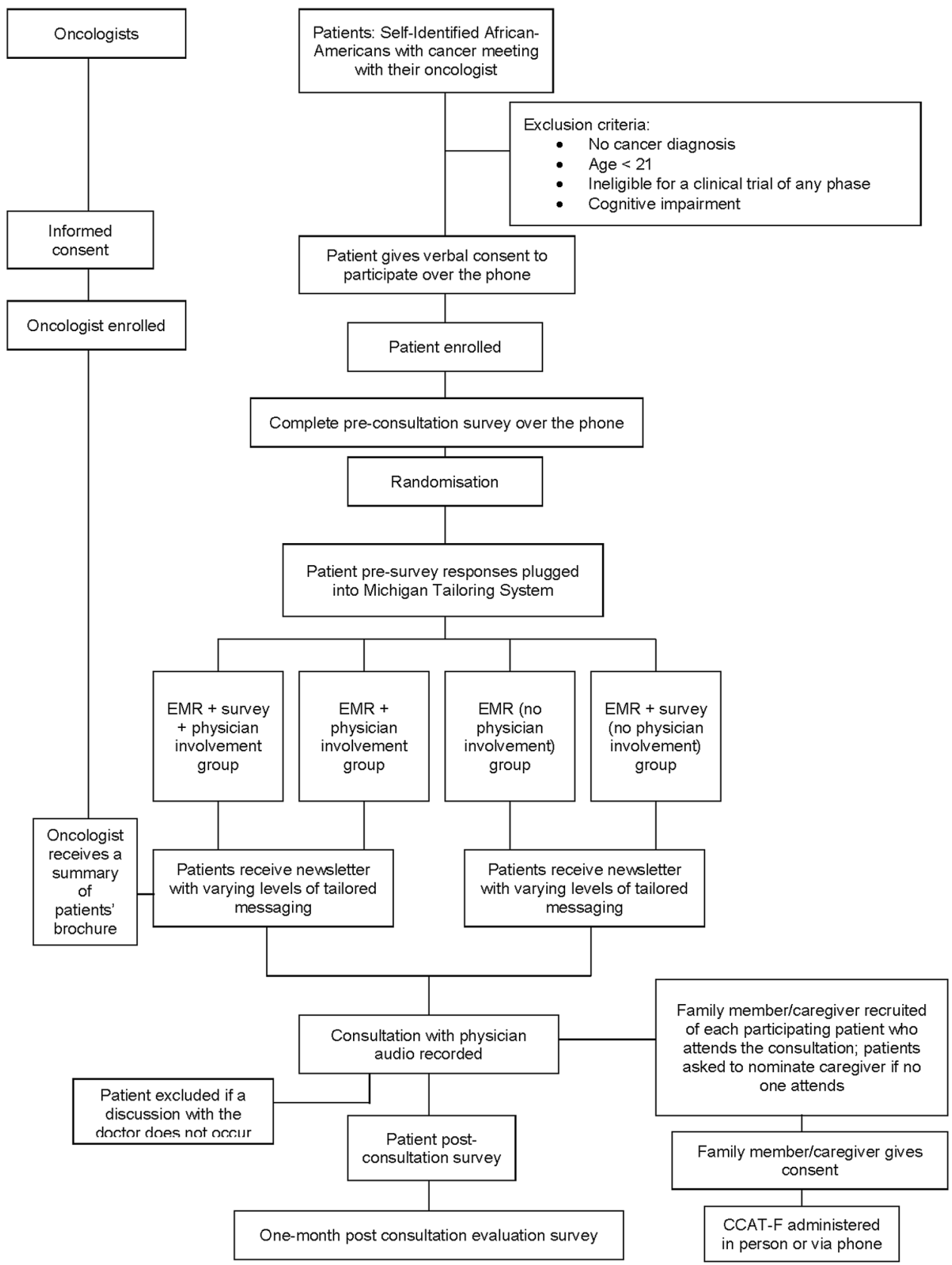

Figure 1 Consort diagram. EMR, electronic medical records.

income; (2) health information such as disease site and severity; and (3) trial information such as the phase of trial offered and previous trial involvement.

\section{Tailoring survey}

We use standardised, psychometrically sound measures to gather information about patients, including their levels of trust in medical research and use these data, augmented by their EMR data, to develop a 'deeper' level of THM. These measures are listed in box 1 .

Participants randomised to deep tailoring complete these measures as part of the tailoring survey in order to develop THM. We include these measures in patient assessment surveys for the other intervention groups. Knowledge/attitudes towards trials and health literacy will be assessed as potential confounding variables. The other variables are assessed as outcomes.

The second step is to develop the three necessary components to deliver tailored messages: (1) the design template; (2) message concepts and (3) tailoring algorithms. We use the Michigan Tailoring System (MTS) software program to support the development of the three components. The MTS is an open-source software toolkit which can create THM for a variety of delivery modes, such as print, web and mobile devices. ${ }^{50}$ We first developed a design template to visualise the message layout, with the goal of producing a two-page, doublesided brochure for participating patients and a one-page summary of the brochure content for the physicians. The design template shows where each message will 


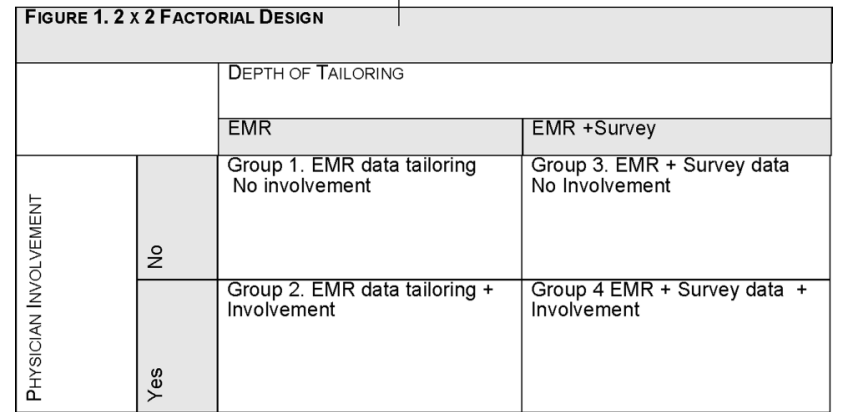

Figure 2 A 2×2 Factorial design. EMR, electronic medical records.

Box 1 Standardised measures to be used for survey tailoring

Knowledge/attitudes towards clinical trials ${ }^{43}$
Health literacy
Trust in medical researchers ${ }^{45}$
Trust in physician
Communication self-efficacy
Information preferences $^{48}$
Decision involvement preferences

appear on the page, how blocks of messages relate to each other and information about the content of each block of messages. ${ }^{37}$ Next, we developed message concepts, for example, shallow versus deep messages concerning medical mistrust, which are the detailed ideas about the content of the THMs. Specific concepts are created for each potential message. ${ }^{37}$ Then, we created a set of tailoring algorithms, which are decision rules that guide every judgement about which THMs each patient will receive $^{37}$ (see figure 3 below for an example).

\section{Implementing and assessing the intervention}

Data from study participants in groups 1 and 2, who are randomised to receive THMs based on their EMR data alone, are entered into the MTS system and their brochures are prepared. These brochures are mailed 1 day after participants have assented to the study. To standardise our data collection across all groups, participants complete the survey described above in box 1 . One week before their scheduled appointment to discuss a CT with their physician, a study research assistant (RA) calls the participant to administer the survey over the telephone. If a participant does not have a telephone, we mail the survey along with a prepaid return envelope

\begin{tabular}{|c|c|c|}
\hline \multicolumn{3}{|c|}{ Fiqure 3. Decision Rule Example. Q5 Trust in Physicians } \\
\hline Question/Statement & Response & Tailored Messaging \\
\hline $\begin{array}{c}\text { (TrustDr5) } \\
\begin{array}{c}\text { "I sometimes distrust my } \\
\text { doctor's opinions and } \\
\text { would like a second one." }\end{array}\end{array}$ & Totally Agree & High Priority Messaging \\
\hline
\end{tabular}

Figure 3 Decision rule example. Q5 trust in physicians. and ask the participant to complete and return the survey within a 24-hour time frame.

Study participants randomised to groups 3 and 4, who are randomised to receive THMs based on both their EMR data and survey responses, complete the survey within 1 week of the participant's scheduled appointment with their physician to discuss a CT. The study RAs call participants to complete the survey over the telephone, with follow-up by mail, as described above for groups 1 and 2, if the participant cannot be reached by telephone. Once the survey responses are received, they are entered into the MTS software along with patient EMR data, and the personalised THMs are instantly generated and colour printed in the format described above. The brochures are mailed to participants to read and participants are encouraged to bring their THM brochure to their consultation to discuss a CT.

Prior to the consultation, physicians of patients randomised to groups 2 and 4 receive a printed summary of each patient's THMs in the patient's notes.

When participants arrive for their appointed consultation, they are met by a study RA. The RA gains written informed consent (see recruitment plan below) and remains present to audio record the consultation. The RA places a digital audiorecorder in the consulting room and then leaves for the remainder of the consultation. The RA collects the audiorecorder at the conclusion of the consultation. At this time, participants complete a second brief survey asking about the tailored message brochure. One family member/caregiver of consented participants is also recruited or identified for recruitment at this time. Consented family member/ caregivers are asked to complete the Communication Assessment Tool for Patients and Families (CCAT-PF), a measure of perceived congruence over the treatment decision (see recruitment plan below).

If a CT was not discussed the participants' involvement in the study is complete and their data and the audio recordings are stored along with all other participant data. If a CT was discussed during the consultation, patients are asked to complete a third survey to assess their immediate, postconsultation impressions of the CT conversation. At this time, the RA identifies a convenient time for the patient to receive a follow-up telephone call at $\sim 1$ month after the consultation visit to complete a final survey. At the appointed time, the RA will call to administer this postconsultation evaluation survey. Patients who do not have a telephone will receive the questionnaire via mail 1 month after the visit along with a prepaid return envelope. These participants will be asked to complete and return the survey within a 24-hour time frame. We chose to collect data 1 month after the consultation in order to ensure that patients have had time to (1) make a treatment decision and (2) have started cancer treatment.

Fidelity plan: We have developed a comprehensive fidelity plan. In summary, we will (1) conduct regular checks to ensure that participants complete the 
phone-administered surveys, (2) use a preconsultation questionnaire to monitor whether participants redeive and understand the THM brochure, (3) conduct regular interviews with physicians in groups 2 and 4 to ascertain that they are reading the THM summary.

\section{Setting}

This study is being conducted at the Massey Cancer Center (MCC), a National Cancer Institute designated centre in Richmond, Virginia, USA. MCC is a safety net hospital that provides inpatient and outpatient services to patients with cancer from a broad catchment area. MCC has a diverse patient population and thus consistently recruits minority patients to trials, mostly AA, at rates above the national average. Thirty-six oncologists have been recruited from the surgical, hematology and radiation oncology services between June 2015 and December 2015.

\section{Sample and recruitment}

\section{Physician identification and accrual}

There are 40 oncologists currently practising at MCC who are eligible to participate in this communication study. Physicians who recruit AA patients to CTs at MCC are eligible to participate. To inform oncologists about the study, a detailed description is presented at clinical conferences and individual discussions are held with physicians as needed. Written consent to participate is obtained at these meetings.

\section{Patient/family member identification and recruitment Patient identification and recruitment}

This study will recruit 357 patients, which is a feasible number given the patient resources available at MCC. This study recruits AA patients who are eligible for a phase I, II or III therapeutic CT, regardless of whether they join the therapeutic trial or not. Eligible patients have a cancer diagnosis, self-identify as AA, are eligible for a therapeutic phase I, II or III CT at MCC, are able to provide informed consent, and are 21 years of age or older.

Study personnel use the Virginia Commonwealth University Health system EMR database to identify all potentially eligible patients with cancer. ${ }^{51}{ }^{52}$ RAs attend weekly multidisciplinary disease team meetings where patient eligibility for CTs is discussed. Once therapeutic trial eligible patients have been identified, RAs obtain physician approval to approach each patient.

The steps involved in patient recruitment are as follows:

Step 1: The RA sends the identified patient a letter that provides a brief description of this study and indicates that they will call the patient within 1 week to discuss the patient's possible participation. Step 2: The RA calls the patient to inform them about the purpose and requirements of the study and asks him/her to consider participation. Each patient who verbally assents is then randomised to one of the four study groups. Step 3:
On the day of the trial consultation, patients receive an information sheet and are asked to provide written consent. (see online supplementary file).

\section{Family member recruitment}

We also recruit one family member/caregiver of each participating patient in order to assess the level of congruence between the patient and their family member over the eventual treatment decision. Consented patients will not be excluded from this study if their family member declines to participate. We recruit family members/caregivers who are nominated by the consented patient as important to the trial decision. Within 1 week of the consultation family members complete a measure of decisional congruence, the CCAT-PF ${ }^{53}$ in person or over the phone.

\section{Randomisation}

The randomisation is conducted off site according to protocols developed by the study statistician. We make use of the randomisation procedures in SAS/STAT. The allocation sequences are stored in a computer file and are unknown to the researchers until the patient is randomised. Block randomisation is used to minimise large imbalances between the four groups. Patients are unaware of the treatment allocation: however, it is not possible to blind oncologists to their patients' treatment allocation. The raters who code audio recordings of the consultations are not aware of the patients' group allocation.

\section{Study aims and hypotheses}

The specific aims and study hypotheses are listed below.

Aim 1: Demonstrate the efficacy of the THM intervention to increase patient activation as measured by coding consultation audio recordings using the Street Patient Activation Coding system. ${ }^{50}$

H1: Group 3 will be more active communicators than group 1.

H2: Group 2 will be more active communicators than group 1 .

H3: Group 4 will be more active communicators than group 3.

Aim 2: Demonstrate the efficacy of the THM to improve patient outcomes.

H4: Group 3 will report higher scores on: trust in their physician, preference achievement, communication selfefficacy, consultation satisfaction and decision outcomes than group 1.

H5: Group 2 will report higher scores than group 1 on the same group of outcomes as $\mathrm{H} 4$.

H6: Group 4 will report higher scores than group 3 on the same group of outcomes as $\mathrm{H} 4$ and $\mathrm{H} 5$.

Aim 3: Explore the association between preconsultation levels of (1) trust in medical researchers, (2) knowledge and attitudes towards CTs, (3) patient family member congruence, and (4) involvement/information preferences and group assignment. 


\section{Study measures}

Data collection: All patient identifiers, questionnaire responses and digital audiorecrdings will be stored on a HIPAA compliant server and will only be available to study staff.

\section{Data extraction from EMR}

Postvisit, we will extract trial data from the EMR including whether the patient enrolled and if not, whether this was due to systemic factors such as insurance status.

\section{Consultation audio recording}

The CT consultation discussions are audio recorded and subsequently coded using the Street Patient Activation Coding system ${ }^{54}$ to gather data about patient-physician communication, including the level of patient activation in the consultation.

\section{Consultation coding for patient activation}

The primary outcome variable used for this study will be patient activation as measured by the Street Patient Activation Coding system. ${ }^{54}$ The coding system will be used to code for three patient participation behaviours (asking questions, expressions of concern and verbally assertive responses) and two physician patient-centered responses (partnership building and supportive talk). The Street Coding system has been used in multiple studies to assess patient activation ${ }^{33} 55$ and has been used successfully as an outcome variable. ${ }^{56}$ Once coding is completed, a composite score is calculated and entered and stored in an Excel database that is exported to SAS for analysis.

\section{Measures}

Questionnaire data

Physician demographics

Participating clinicians provide information about their age, gender, race, specialty, years of practice and years recruiting patients to phase I, II and III CTs at the time when they are recruited to the communication study.

\section{Patient questionnaires}

Patients complete questionnaires prior to their consultation, immediately postconsultation and 1 month after their consultation. All measures have been previously published and are standardised and validated scales. Table 1 below provides the details of each of the scales and an administration schedule.

\section{Power analysis and sample size calculation}

We computed power to detect cross-sectional group differences on the primary outcome, patient activation using $2 \times 2$ analysis of covariance (ANCOVA) with two covariates which is the least powered scenario in the proposed analytic plan. Using previous findings reporting a mean count of active patient utterances from the Street Coding system ${ }^{54}$ used in a sample of African-American patients of $5.9, \mathrm{SD}=5.5$, we compute sample size needed to detect a $1 / 2 \mathrm{SD}$ difference between groups, which represents an effect size of 0.223 . Power is 0.90 with an $\mathrm{N}=357$.

\section{Data analyses}

All analyses will be conducted as intention-to-treat given available data including outcomes extracted from medical records even if the participant does not complete the full research protocol, for example, becomes too ill. We will conduct post hoc exploratory analyses to examine whether the intervention was more effective for some groups than others, for example, by age and gender.

\section{Aim 1}

Once descriptive (univariate) analyses are completed, we will use bivariate statistics and means testing for hypotheses testing. Bivariate analyses will first be used to examine depth of tailoring, physician involvement and patient activation. ANCOVA will be used to evaluate the

Table 1 Questionnaires and assessment tools used in the study Questionnaire content and schedule — preclinical and postclinical trials consultation

\begin{tabular}{llll}
\hline Measures & Preconsultation & Immediate post & One month post \\
\hline Knowledge/attitudes towards clinical trials $^{43}$ & $\checkmark$ & & $\checkmark$ \\
Trust in medical researchers $^{45}$ & $\checkmark$ & $\checkmark$ & $\checkmark$ \\
Trust in physician $^{46}$ & $\checkmark$ & $\checkmark$ & $\checkmark$ \\
Information preferences $^{48}$ & $\checkmark$ & $\checkmark$ & \\
Decision involvement preferences $^{49}$ & $\checkmark$ & $\checkmark$ & \\
Communication self efficacy $^{47}$ & $\checkmark$ & $\checkmark$ & \\
Patient/family communication congruence $^{53}$ & $\checkmark$ & & \\
Health literacy $^{44}$ & $\checkmark$ & $\checkmark$ & $\checkmark$ \\
Understanding of clinical trials $^{57}$ & & $\checkmark$ & $\checkmark$ \\
Decisional conflict $^{58}$ & & & $\checkmark$ \\
Satisfaction with the decision $^{59}$ & & & $\checkmark$ \\
Satisfaction with consultation communicationn $^{60}$ & & & $\checkmark$ \\
Decision regret $^{61}$ & & & \\
\hline
\end{tabular}


main effect of depth of tailoring, the main effect of physician involvement and possible interactions between depth of tailoring and physician involvement on patient activation.

\section{Aim 2}

Bivariate analyses will first be used to examine depth of tailoring, physician involvement and trust in their physician, levels of achievement of information and involvement preferences, levels of communication self-efficacy, satisfaction with the consultation communication, satisfaction with their decision, levels of decisional conflict and levels of decision regret. Multivariate ANCOVA (MANCOVA) will be used to evaluate the main effect of depth of tailoring, the main effect of physician involvement and possible interactions between depth of tailoring and physician involvement on all dependent variables.

\section{Aim 3}

Bivariate analyses will first be used to examine depth of tailoring, physician involvement and trust in medical researchers, knowledge and attitudes towards CTs, patient/family member congruence and involvement/ information preferences and health literacy. MANCOVA will be used to evaluate the main effect of depth of tailoring, the main effect of physician involvement and possible interactions between depth of tailoring and physician involvement on patient activation using each of these characteristics as well as phase of trial as covariates. Repeated measures MANCOVA will be constructed similarly to the proposed MANCOVA to examine stability and/or change in characteristics assessed over time (eg, decisional conflict).

\section{Expected achievement}

Using established methods of THM, we are directly intervening in the physician-AA patient CT consultation communication process to increase patient activation in the consultation to potentially improve a range of relevant patient outcomes. Since we are extending the use of the THM intervention, by assessing depth of tailoring and physician involvement in the intervention, we anticipate that our results will inform scientific knowledge and influence optimal use of THM in multiple clinical settings.

\section{DISCUSSION}

Therapeutic CTs test the efficacy of newly emerging cancer treatments, yet few patients with cancer participate, thus slowing the progress of new treatments and their implementation to fight cancer. African-American patients with cancer are among the least likely to be offered to join a CT and among the least likely to join a trial if asked. Ineffective consultation communication has been identified as a significant factor contributing to AA patient refusal to join a trial. We suggest that using
THM coupled with physician involvement in the intervention process has the potential to assist AA patients to be more engaged and active communicators, which in turn may help overcome barriers to trial enrolment and improve significant patient outcomes.

THM increase the relevance of health information by targeting individuals' personalised needs based on a rigorous assessment of their characteristics and preferences. ${ }^{37}$ No studies to date have explored the impact of providing tailored CT information to promote active AA participation in CT consultations. Thus, this project extends the use of THM into a novel clinical context with the potential to reduce health disparities associated with AA recruitment to cancer CTs. This study is innovative in that we will test the impact of shallow versus deep tailoring to provide new information about the depth of tailoring required to increase patient activation. Further, in spite of the dynamic nature of consultation communication, no studies have explored the additional impact of involving patients and physicians in THM interventions. These data can potentially be used to inform and impact optimal methods for using tailored health messaging.

There are three main limitations to this study. First, our own data suggest that communication challenges differ between phases I, II and III trials. For example, physicians may be more paternalistic with patients facing a phase I CT than those facing a phase III trial. ${ }^{21}$ Our sample size does not allow us to stratify the randomisation by trial phase as this would almost triple the sample required. Second, we will recruit participants from MCC, a safety net hospital. However, we will not cover communication issues particular to the community oncology setting. Third, physician training to use the patients' THM summary will not be provided. Future research could usefully add and assess such a training component.

\section{ETHICS AND DISSEMINATION PLAN}

The study is registered at Clinical trials.gov, identifierNCT02356549.

Patient recruitment started in April 2016 and is expected to close in June 2018.

This program is designed to be 'turnkey', in that all of the core processes needed to implement the program will be finalized on project completion and readily available at no cost and can be downloaded from our own local websites and other national websites. To facilitate use of the THM intervention in diverse settings, we will convene 'user groups' at three major US cancer centres. Input from these user groups will be used to develop an implementation guide. To facilitate dissemination, we will post all materials and the implementation guide in publicly available locations. We will also attend scientific meetings and publish manuscripts that detail the study.

\section{Author affiliations}

${ }^{1}$ Department of Health Behavior and Policy, Virginia Commonwealth University School of Medicine, Richmond, Virginia, USA 
${ }^{2}$ Department of Health Promotion, Education and Behavior, Arnold School of Public Health, University of South Carolina, Columbia, South Carolina, USA ${ }^{3}$ Siminoff Research Group, College of Public Health, Temple University, Philadelphia, Pennsylvania, USA

${ }^{4}$ Massey Cancer Center, Virginia Commonwealth University School of Medicine, Richmond, Virginia, USA

Contributors RFB, RD, SG, DC and GG developed the initial project idea, contributed to the intervention development, enacted the intervention, aided in developing and reviewing the manuscript. MWG developed the initial project idea, developed the analysis plan, sample size calculation, randomisation techniques. She also aided in developing and reviewing the manuscript. JA, $\mathrm{ML}$ and JW contributed to the intervention development, enacted the intervention and aided in developing and reviewing the manuscript.

Funding American Cancer Society Research Scholar Grant (RSG-14-227-01 CPPB).

Competing interests None declared.

Ethics approval Virginia Commonwealth University Institutional Review Board.

Provenance and peer review Not commissioned; externally peer reviewed.

Data sharing statement At this time patient data have yet to be collected. Once data are collected it will be available by emailing RFB at Richard. Brown@vcuhealth.org.

Open Access This is an Open Access article distributed in accordance with the Creative Commons Attribution Non Commercial (CC BY-NC 4.0) license, which permits others to distribute, remix, adapt, build upon this work noncommercially, and license their derivative works on different terms, provided the original work is properly cited and the use is non-commercial. See: http:// creativecommons.org/licenses/by-nc/4.0/

\section{REFERENCES}

1. Adams-Campbell LL, Ahaghotu $\mathrm{C}$, Gaskins $\mathrm{M}$, et al. Enrolment of African Americans onto clinical treatment trials: study design barriers. J Clin Oncol 2004;22:730-4.

2. Avis $\mathrm{NE}$, Smith $\mathrm{KW}$, Link $\mathrm{Cl}$, et al. Factors associated with participation in breast cancer clinical trials. J Clin Oncol 2006;24:1860-7.

3. Ellis P, Butow PN, Tattersall MHN, et al. Randomised clinical trials in oncology: understanding and attitudes predict patients willingness to participate. J Clin Oncol 2001;19:3554-61.

4. Lara PN, Higon N, Lim N, et al. Prospective evaluation of clinical trial accrual patterns: identifying potential barriers to enrolment. J Clin Oncol 2001:19:1728-33.

5. Howerton MW, Gibbons MC, Baffi CR, et al. Provider roles in the recruitment of underrepresented populations to cancer clinical trials. Cancer 2007;109:465-76.

6. Tilburt J, Ford JG, Howerton MW, et al. Applying justice in clinical trials for diverse populations. Clin Trials 2007;4:264-9.

7. Bartlett C, Doyal L, Ebrahim S, et al. The causes and effects of socio-demographic exclusions from clinical trials. Health Technol Assess 2005;9:1-152.

8. Britton A, McKee M, Black N, et al. Threats to the applicability of randomised trials, exclusions and selective participation. $J$ Health Serv Res Policy 1999;4:112-21.

9. Branson RD, DAvis KJ, Butler KL. African Americans participation in clinical research; importance, barriers and solutions. Am J Surg 2007;193:32-9.

10. Swanson GM, Bailer JC. Selection and description of cancer clinical trials participants: science or happenstance. Cancer 2002:95:950-9.

11. Ford JG, Howerton MW, Lai Gabriel Y, et al. Barriers to recruiting underrepresented populations in cancer clinical trials: a systematic review. Cancer 2007;112:228-42.

12. Goss W, Lopez AM, Brown CL, et al. American Society of Clinical Oncology policy statement: disparities in cancer care. J Clin Oncol 2009;27:2882-4.

13. Ellis $P$, Dowsett SM, Butow PN, et al. Attitudes to randomised clinical trials among outpatients attending a medical oncology clinic. Health Expect 1999;2:33-43.

14. Cunny KA, Miller HW. Participation in clinical drug studies: motivations and barriers. Clin Therapy 1994;16:273-82. discussion 271-2.
15. Corbie Smith G, Thomas SB, St George DM. Distrust, race and research. Arch Intern Med 2002;162:2458-63.

16. Fallowfield $\mathrm{L}$. Can we improve the professional personal fulfilment of doctors in cancer medicine. Br J Cancer 1995;71:1132-3.

17. Agrawal M, Grady C, Fairclough DL, et al. Patient decision making process regarding participation in phase I oncology research. J Clin Oncol 2006;24:4479-83.

18. Albrecht TL, Penner LA, Cline RJW, et al. Studying the process of clinical communication: issues of context, concepts and research directions. J Health Comun 2009;14:47-56.

19. Albrecht TL, Ruckdeschel JC, Riddle JC, et al. Communication and decision making about cancer clinical trials. Patient Educ Couns 2003:50:39-42.

20. Brown RF, Butow PN, Ellis $\mathrm{P}$, et al. Seeking informed consent to cancer clinical trials: describing current practice. Soc Sci Med 2004;58:2445-57.

21. Brown RF, Bylund CL, Siminoff LA, et al. Seeking informed consent to phase I cancer clinical trial: Identifying oncologists' communication strategies. Psychooncology 2010;20:361-8.

22. Fallowfield L, Jenkins V, Farewell V, et al. Efficacy of a Cancer research UK communication skills training model for oncologists: a randomised controlled trial. Lancet 2002;359:650-6.

23. Stiles WD, Putnam SM, James S, et al. Dimensions of patient and physician roles in medical interviewing. Soc Sci Med 1979;13A:335-41.

24. Beisecker AE, Beisecker TD. Patient information-seeking behaviors when communicating with doctors. Med Care 1990;28:19-28.

25. Kindelan K, Kent G. Concordance between patients' information preferences and general practitioners' perceptions. Psychol Health 1987;1:399-409.

26. Strull WM, Lo B, Charles G. Do patients want to participate in medical decision making? J Am Med Assoc 1984;252:2990-4.

27. Breitsameter C. Medical decision-making and communication of risks: an ethical perspective. J Med Ethics 2010;36:349-52.

28. Charles C, Gafni A. Shared treatment decision making and the use of decision aids. In: Kissane D, Bultz BD, Butow PN, Finlay IG, eds. Handbook of communication in oncology and palliative care. New York: Oxford, 2010:41-50.

29. Siminoff LA. The ethics of communication in cancer and palliative care. In: Kissane D, Bultz BD, Butow PN, Finlay IG, eds. Handbook of communication in oncology and palliative care. New York: Oxford University Press, 2010:51-61.

30. Brown RF, Butow PN, Wilson-Genderson M, et al. Meeting breast cancer patients' decision making preferences in oncology consultations: impact on decision related outcomes. J Clin Oncol 2012;30:857-62.

31. Gattellari M, Butow PN, Tattersall MH. Sharing decisions in cancer care. Soc Sci Med 2001;52:1865- 78.

32. Johnson RL, Roter D, Powe NR, et al. Patient race/ethnicity and quality of patient-physician communication during medical visits. Am J Public Health 2004;94:2084-90.

33. Street RLJ, Gordon HS, Ward MM, et al. Patient participation in medical consultations: why some patients are more involved than others. Med Care 2005;43:960-9.

34. Gordon HS, Street RL Jr, Sharf BF, et al. Racial differences in trust and lung cancer patients' perceptions of physician communication. J Clin Oncol 2006;24:904-9.

35. Fouad MN. Enrolment of minorities in clinical trials: Did we overcome the barriers? Contemp Clin Trials 2009;30:103-4.

36. Sparks L, Villagran M. Patient and provider interaction: a global health communication perspective. Cambridge, UK: Polity Press, 2010.

37. Kreuter MW, Farrell DW, Olevitch LR, et al. Tailoring health messages: Customizing communication with computer technology. UK: Routledge, 2013.

38. Kreuter MW, Sugg-Skinner C, Holt CL, et al. Cultural tailoring for mammography and fruit and vegetable intake among low-income African-American women in urban public health centers. Prev Med 2005;41:53-62

39. Noar SM, Benac CN, Harris MS. Does tailoring matter? Meta-analytic review of tailored print health behavior change interventions. Psychol Bull 2007;133:673-93.

40. Moher D, Hopewell S, Schulz KF, et al. CONSORT 2010 explanation and elaboration: updated guidelines for reporting parallel group randomised trials. BMJ 2010;340:c869.

41. Kreuter MW. Toward more effective health communication: comparing the effects of tailored, personalized, and untailored messages in a randomized trial. Annual Meeting of the American Public Health Association. 1997. IN, 1997.

42. Kreuter MW, Strecher VJ, Harris R, et al. Are patients of women physicians screened more aggressively? A prospective study of physician gender and screening. J Gen Intern Med 1995;10:119-25. 
43. Ellis PM, Butow PN, Tattersall MHN, et al. A randomised trial evaluating the impact of an education booklet on willingness to join randomised trials. Clinical Oncological Society of Australia, Annual Scientific Conference. 1999. Melbourne, 1999.

44. Chew LD, Bradley KA, Boyko EJ. Brief questions to identify patients with inadequate health literacy. Fam Med 2004;36:588-94.

45. Hall MD, Camacho F, Lawlor JS, et al. Measuring trust in medical researchers. Med Care 2006;44:1048-53.

46. Thom DH, Ribisl KM, Stewart AL, et al. Further validation and reliability testing of the trust in physician scale. The Stanford Trust Study Physicians. Med Care 1999;37:510-17.

47. Maly RC, Frank JC, Marshall GN, et al. Perceived Efficacy in Patient-Physician Interactions (PEPPI): validation of an instrument in older persons. J Am Geriatr Soc 1998;46:889-94.

48. Cassileth BR, Zupkis RV, Sutton-Smith K, et al. Information and participation preferences among cancer patients. Ann Intern Med 1980;92:832-6.

49. Llewellyn-Thomas HA, McGreal MJ, Thiel EC. Cancer patients decision making and trial entry preferences: the effects of "framing" information about short term toxicity and long term survival. Med Decis Making 1995;15:4-12.

50. Center for Health Communications Research. Michigan Tailoring System. (cited 2012 2.10.12). http://chcr.umich.edu/mts/index.php.

51. Penberthy L, Brown RF, Puma F, et al. Automated matching software for clinical trials eligibility; measuring efficiency and flexibility. Contemp Clin Trials 2010;31:207-17.

52. Penberthy L, Brown RF, Wilson-Genderson M, et al. Barriers to therapeutic clinical trials enrollment: differences between
African-American and white cancer patients identified at the time of eligibility assessment. Clinical Trials. 2012;9:788-97.

53. Siminoff LA, Zyzanski SJ, Rose JH, et al. The cancer communication assessment tool for patients and families (CCAT-PFA new Measure). Psychooncology 2008;17:1216-24.

54. Street RL, Millay B. Analyzing patient participation in medical encounters. Health Commun 2001;13:61-73.

55. Street RL, Gordon HS. Companion participation in cancer consultations. Psychooncology 2008;17:244-591.

56. Cegala DJ, Chisolm DJ, Nwomeh BC. Further examination of the impact of patient participation on physicians' communication style. Patient Educ Couns 2012;89:25-30.

57. Joffe S, Cook E, Francis V, et al. Quality of informed consent: a new measure if understanding among research subjects. $J$ Natl Cancer Inst 2001;93:139-47.

58. O'Connor A, O'Brien-Pallas LL. Decisional conflict. In: McFarland GK, McFarland EA, eds. Nursing diagnosis and interventions. Toronto, Canada: C V Mosby, 1989:573.

59. Holmes-Rovner M, Kroll J, Schmitt N, et al. Patient satisfaction with health care decisions: the satisfaction with decision scale. Med Decis Making 1994;16:58-64.

60. Roter DL. Patient participation in the patient-provider interaction: the effects of patient question asking on the quality of interaction, satisfaction and compliance. Health Educ Monogr 1977;5: 281-315.

61. Brehaut Jamie JC, O'Connor Annette M, Wood TJ, et al. Validation of the Decision Regret Scale. Med Decis Making 2003:23:281-92. 